\title{
Removal of Phosphate from Aqueous Solutions Using Chemically Synthesized Vaterite Polymorph of Porous Calcium Carbonate Nanoparticles under Optimized Conditions
}

\author{
D. D. T. T. Darshana Senarathna $\mathbb{D}^{1}{ }^{1}$ K. H. D. Namal Abeysooriya, ${ }^{2}$ S. P. Dunuweera $\mathbb{D},{ }^{3}$ \\ B. P. K. Ekanayake, ${ }^{2}$ W. M. H. K. Wijenayake, ${ }^{1}$ and R. M. G. Rajapakse ${ }^{3}{ }^{3}$ \\ ${ }^{1}$ Department of Aquaculture and Fisheries, Faculty of Livestock Fisheries \& Nutrition, Wayamba University of Sri Lanka, \\ Makandura, Gonawila (NWP), Sri Lanka \\ ${ }^{2}$ Environmental Science Degree Programme, Faculty of Science, University of Peradeniya, Peradeniya 20400, Sri Lanka \\ ${ }^{3}$ Department of Chemistry, Faculty of Science, University of Peradeniya, Peradeniya 20400, Sri Lanka
}

Correspondence should be addressed to R. M. G. Rajapakse; rmgr@pdn.ac.lk

Received 28 May 2020; Revised 6 August 2020; Accepted 28 August 2020; Published 15 September 2020

Academic Editor: Ahmad Hosseini Bandegharaei

Copyright (C) 2020 D. D. T. T. Darshana Senarathna et al. This is an open access article distributed under the Creative Commons Attribution License, which permits unrestricted use, distribution, and reproduction in any medium, provided the original work is properly cited.

\begin{abstract}
Eutrophication is one of the most adverse impacts of nutrient contamination of water bodies where the phosphate is considered to be the primary limiting factor. The vaterite polymorph of porous calcium carbonate nanoparticles (VPCCNPs) were synthesized and used to remove orthophosphate ions in water. In this study, the VPCCNPs were synthesized chemically, using calcium acetate and sodium bicarbonate in a water-ethylene glycol media, at a temperature of $100^{\circ} \mathrm{C}$, in a reaction time of 24 hours. Synthesized nanoparticles were characterized by X-ray diffractometry to confirm that the crystalline phase of calcium carbonate formed is spherical vaterite polymorph. Scanning electron microscopy coupled with energy dispersive X-ray analysis further confirms the spherical shape of the vaterite nanoparticles and the presence of only calcium, carbon, and oxygen thus showing high purity of the synthesized calcium carbonate nanoparticles. The dynamic laser light scattering-based particle size analysis (DLS) shows the average particle size to be $25.5 \mathrm{~nm}$. The Fourier transform infrared spectroscopy was used to find functional groups before and after the adsorption of phosphate by vaterite nanoparticles. The phosphate removal efficiency of synthesized nanoparticles was tested with different concentrations of phosphate solutions (2-80 mg/L), pH levels (5-12), adsorbent dosages $(0.025-0.250 \mathrm{~g})$, and contact times (5-120 $\mathrm{min})$. Ion chromatography was used to analyse the phosphate concentrations in water samples. The maximum phosphate removal percentage of $100 \%$ was obtained with $50 \mathrm{~mL}$ of $2 \mathrm{mg} / \mathrm{L}$ phosphate solution and $0.15 \mathrm{~g}$ of the synthesized nanoparticle. Adsorption data were well fitted with the Langmuir adsorption isotherm model and the pseudo-second-order kinetic model with $R^{2}$ of 0.99 and 0.98 (rate constant $-0.083 \mathrm{~g} \mathrm{~g}^{-1} \mathrm{~min}^{-1}$ ), respectively. The presence of $\mathrm{F}^{-}$, $\mathrm{NO}_{3}^{-}$, and $\mathrm{SO}_{4}^{2-}$ has no effect on phosphate adsorption since $100 \%$ phosphate removal is obtained in the presence of these ions. Furthermore, the particle shows a 100\% removal of orthophosphate ions available in eutrophic water regardless of the presence of many other ions in natural water bodies. The study presents a viable option for removing excess phosphate in natural water to desirable levels as a means for controlling eutrophication.
\end{abstract}

\section{Introduction}

Nutrient contamination of water is a serious problem for water bodies worldwide which leads to uncontrollable eutrophication. The eutrophication is considered to be one of the main causes that makes structural changes to the natural ecosystems such as stimulation of the production of algae and aquatic plants, gradual depletion of fish species, deterioration of water quality, and other effects [1]. After those organisms are dead, bacterial degradation of their biomass and blooming of harmful bacteria lead to the depletion of the dissolved oxygen level in the aqueous environment thus 
creating a state of hypoxia plummeting the biodiversity in the ecosystem $[2,3]$.

Recent studies have shown that the primary limiting factor for eutrophication is phosphorus [4]. The availability of phosphorus generally leads to excessive algae and plant growth while causing a severe reduction in water quality. Phosphorus is one of the essential nutrients for plants to live and is the limiting factor for aquatic plant growth in many freshwater ecosystems [1]. Phosphate usually adheres tightly to soil and is mainly transported due to erosion. Once the phosphate is translocated into a lake, or a freshwater ecosystem, its extraction into the water is slow, making it difficult for reversing the consequences of eutrophication [5].

In an aqueous environment, phosphorus is usually available in the pentavalent form as orthophosphate, pyrophosphate, organic phosphate esters, longer-chain polyphosphates and phosphodiesters, and organic phosphonates. These phosphorus compounds could be hydrolyzed to orthophosphate, which is the only form that could be utilized by bacteria, algae, and plants [6]. In wastewater discharges, the phosphorus is available in forms of phosphate $\left(\mathrm{H}_{2} \mathrm{PO}_{4}^{-}, \mathrm{HPO}_{4}^{2-}\right.$, and $\left.\mathrm{PO}_{4}^{3-}\right)$, organic phosphate and polyphosphate [7].

About $0.025 \mathrm{mg} \mathrm{L}^{-1}$ of total phosphorus can accelerate the eutrophication in lakes [8]. Lakes having the phosphorus levels between 0.01 and $0.03 \mathrm{mg} \mathrm{L}^{-1}$ are considered as uncontaminated lakes while the maximum recommended phosphorus level to protect the integrity of an aquatic ecosystem is around $0.10 \mathrm{mg} \mathrm{L}^{-1}[8]$. Intensive agriculture with excessive use of fertilizers, animal wastes, mining of phosphate for industrial uses, household uses of detergents, and municipal sewage-like anthropogenic activities are the major sources of phosphate in natural water bodies [9]. Therefore, removal of excess phosphate present in water bodies has become vital.

Some of the conventional treatment methods for phosphate removal are biological removal, precipitation, adsorption, and ion exchange [10]. Electrodialysis and reverse osmosis are some of the novel techniques developed to control the phosphate in water [11]. However, most of these technologies have disadvantages due to their high cost and centralized nature [12]. On the other hand, adsorption techniques have several advantages such as high efficiency, relatively inexpensive or cost-effective operation, and the potential for saving and recycling of phosphate resources. Recently, considerable attention has been paid to the development of effective and low-cost or inexpensive adsorbents from naturally available materials and compounds using novel technologies such as nanotechnology.

Various adsorbents have been tested for different forms of phosphorous removal from aqueous solutions so far. Low-cost natural materials and biosorbents such as waste oyster shells with considerable phosphate removal percentages ( 98\%) [13], used alum sludge (62.5\%) [14], phosphate mine wastes (93\%) [15], fly ash (99\%) [16], blast furnace slag [17], different materials in constructed wetlands (85\%) [18], Sargassum angustifolium modified by molybdate (53.4\%) [19], and municipal solid waste (MSW) compost ash (100\%) [20] are some of the successful attempts for phosphate removal. Although most of these adsorbents are less in cost, they are associated with significant drawbacks also. Since some of these materials are byproducts of waste or sewage, there might be a risk of contamination with toxic microorganisms when treating the drinking water or aquaculture ponds. Also, some of them may be toxic to biota when used in aquaculture ponds or in an ecosystem with a broad biodiversity. Therefore, finding alternative adsorbents that are harmless to the ecosystem is still a challenge.

Calcium carbonate particles have vast technological applications in different industries such as building, pharmaceutical, paper, textile, cosmetics, toothpaste, paint, glove, food and beverage, ink, plastic film, and many other manufacturing industries due to some properties such as increasing the production volume and improving processing performance ability. In medicine, calcium carbonate is used as an inexpensive dietary supplement of calcium and as a phosphate binder for the treatment of hyperphosphatemia, particularly in cancer patients. In all these practical applications, $\mathrm{CaCO}_{3}$ macro- or microparticles are currently used. But if those particles can be replaced by respective nanoparticles, then the material requirement can be reduced drastically due to the extremely large surface area to volume ratio of nanoparticles [21]. Furthermore, the pure calcium carbonate and natural biomaterials which contain calcium carbonate as a main component have been identified as an effective adsorbent to be used in water treatment industries. For example, bivalve shells are used in methylene blue removal [22], sepia shell-based composite for cationic and anionic dye removal [23], and calcium carbonate nanoparticles for removing $\mathrm{Cu}$ (II) in water [24]. In our previous studies, we have shown vaterite polymorph of porous calcium carbonate (VPPCC) nanoparticles can be used to remove fluoride from water sources efficiently [25]. The vaterite form has the advantage that the particles are spherical in shape and contain high surface area due to the presence of a high percentage of pores in them. It has been shown that $50 \%$ of the interior of the vaterite nanoparticles prepared by the methods used here are pores exposing the interior surfaces thus giving rise to a large number of sites for adsorption [21]. Vaterite is the thermodynamically least stable polymorph of calcium carbonate $[26,27]$. Although vaterite has the same chemical composition as calcite (rhombohedral) and aragonite (orthorhombic), it has a different crystal structure in terms of symmetry, the orientation of $\mathrm{CO}_{3}{ }^{2-}$ ions, and coordination environment of $\mathrm{Ca}^{2+}$ ions [21]. To synthesize, the vaterite polymorph requires special techniques such as the use of a very specific polymer like polyaniline. Furthermore, the adsorptive removal of phosphate species using calcite and aragonite has been already studied but not with vaterite. Therefore, it is important to study the applicability of vaterite in phosphate removal to see whether it would give improved phosphate removal when compared to other two polymorphs as calcium carbonate is a nontoxic material that can be used specially in aquaculture industries to maintain large fish ponds and in fisheries where harvest fish from natural water bodies. On the other hand, the use of other metal oxide nanomaterials (titanium dioxide nanoparticles [28], iron oxide nanoparticles [29], and zinc oxide nanoparticles [30] and some adsorbents might be toxic to both the human 
and animals due to their photocatalytic activity generating reactive oxygen species.

In this publication, we present an extended study for the use of vaterite polymorph of calcium carbonate nanoparticles to remove phosphate ions in water in order to protect natural water bodies, aquaculture ponds, and other aquatic ecosystems from phosphate-based eutrophication while protecting the biodiversity and safety of aquatic food resources. The objectives of this study were to optimize parameters responsible for phosphate adsorption on vaterite polymorph of porous calcium carbonate (VPPCC) nanoparticles and to use these optimized parameters for evaluating equilibrium adsorption isotherm studies as well as kinetic studies. The results obtained with VPPCC nanoparticles are compared with those that are available in the literature for other adsorbents to show that VPPCC nanoparticles have superior properties over other commonly used materials for removing phosphate from aquatic environments irrespective of whether other anions are present or not.

\section{Materials and Methods}

2.1. Materials. All the chemicals used were of analytical grade unless otherwise specified. Calcium acetate $\mathrm{Ca}\left(\mathrm{CH}_{3} \mathrm{COO}\right)_{2}$, sodium bicarbonate $\mathrm{NaHCO}_{3}$, and trisodium phosphate $\left(\mathrm{Na}_{3} \mathrm{PO}_{4}\right)$ were purchased from Sigma-Aldrich and were used without further purification. Ethylene glycol (99\% purity) was purchased from Avon Pharmo Chemicals Ltd. Water used was distilled and deionized.

2.2. Methods. The VPCCNPs were synthesized by the reaction between calcium acetate and sodium bicarbonate in a solvent mixture of water and ethylene glycol. This is a modification of a method which was used elsewhere [21, 31]. First, two solutions were prepared separately: solution (a)-mixture of $\mathrm{Ca}\left(\mathrm{CH}_{3} \mathrm{COO}\right)_{2}(100.0 \mathrm{~mL}, 0.50 \mathrm{M}), \mathrm{H}_{2} \mathrm{O}$ $(40.0 \mathrm{~mL})$, and EG $(100.0 \mathrm{~mL})$; solution (b)-mixture of $\mathrm{NaHCO}_{3}(100.0 \mathrm{~mL}, 0.50 \mathrm{M}), \mathrm{H}_{2} \mathrm{O}(40.0 \mathrm{~mL})$, and EG $(100.0 \mathrm{~mL})$. Then, two solutions were mixed slowly in a dropwise manner under stirring at $150 \mathrm{rpm}$. Stirring was continued for further $48 \mathrm{~h}$, and the resulted suspension was centrifuged and filtered. Then, the obtained solid mass was washed first with ethanol and then with distilled water and dried, at $80^{\circ} \mathrm{C}$, for $5 \mathrm{~h}$, in a vacuum oven.

The size distribution was investigated using DLS, CILAS particle size analyser-NANO DS. To do so, $0.005 \mathrm{~g}$ of VPPCC was dispersed in $30.0 \mathrm{~mL}$ of distilled water and sonicated for $15 \mathrm{~min}$. Then, the colloidal solution was diluted with distilled water in a 1:1 ratio and again sonicated, and the suspension was used for size distribution analysis. Morphological and elemental analyses of the chemically synthesized nanoparticles before and after the phosphate adsorption were done using Hitachi SU6600 Scanning Electron Microscope (SEM) and energy-dispersive X-ray spectroscopy (EDX). SEM was carried out after depositing gold on prepared nanoparticles to an optimum $5 \mathrm{~nm}$ thickness. The crystallographic analysis of VPPCC nanoparticles, before and after the phosphate adsorption, was performed using the Siemens D5000 powder X-ray Diffractometer (XRD). Fourier transform infrared (FTIR) spectroscopy was done using the Shimadzu IR Prestige-21 spectrometer using the $\mathrm{KBr}$ pellet method to identify chemical composition and bonding present before and after the phosphate adsorption. The sample was mixed with dry KBr solid in a 1:40 mass ratio for pellet preparation.

To prepare phosphate ion solution, trisodium phosphate (98\%) solid was dissolved in distilled, deionized water in a $1.0 \mathrm{~L}$ volumetric flask to prepare a $1000 \mathrm{mg} / \mathrm{L}$ of stock phosphate solution. This stock solution was used to prepare the $4 \mathrm{mg} / \mathrm{L}$ orthophosphate solution and other concentration ranges used in the isotherm studies and also for the optimization with respect to initial phosphate concentration. Optimization studies were done using a $50.0 \mathrm{~mL}$ volume of phosphate solution, at room temperature $\left(25 \pm 2^{\circ} \mathrm{C}\right)$, with a $150 \mathrm{rpm}$ shaking speed, for analysing the parameters affecting phosphate adsorption such as contact time, initial phosphate concentration, $\mathrm{pH}$ of the solution, and the particle dosages. Table 1 depicts the conditions used in parameter optimization studies.

At the end of each optimization process, solutions were kept for $30 \mathrm{~min}$ for settling and were then filtered using filter papers. Finally, the remaining phosphate concentration of each solution was measured using ion chromatography (930 Compact IC Flex, Metrohm). The $\mathrm{pH}$ changes during the treatment were tested under all optimized conditions. First, the solution was treated under optimized conditions with the synthesized nanoparticles and the $\mathrm{pH}$ of the solution was measured in 2 min time intervals and recorded.

Kinetic studies were done with $3.00 \mathrm{~g}$ of adsorbent in $1.0 \mathrm{~L}$ of $2 \mathrm{mg} / \mathrm{L}$ orthophosphate solution which was maintained with the optimum conditions. The solution was stirred at $150 \mathrm{rpm}$ speed for $60 \mathrm{~min}$. About $3 \mathrm{~mL}$ of samples was then withdrawn, using a dropper, in 10 different time gaps during the stirring, and their phosphate concentration was analysed using the ion chromatography. Adsorption isotherm study was performed with $50.0 \mathrm{~mL}$ of phosphate initial concentrations ranging from 2 to $80 \mathrm{mg} / \mathrm{L}$ using $0.15 \mathrm{~g}$ adsorbent dosage for each sample, under optimized conditions, at room temperature. Solutions were stirred for $30 \mathrm{~min}$, at $150 \mathrm{rpm}$, and allowed to settle for another $30 \mathrm{~min}$. Then, the phosphate concentration of treated samples was measured using ion chromatography (930 Compact IC Flex, Metrohm). The effect of other anions, commonly present in environmental water samples, on phosphate removal by VPPCC nanoparticles, was studied as follows. Removal behavior of orthophosphate by VPPCC nanoparticles in the presence of sulphate, fluoride, and nitrate was examined at the higher, equal, and lower concentrations of those ions compared to the concentration of orthophosphate. $50.0 \mathrm{~mL}$ of the synthesized solution (mixture of ions) was taken, and $0.15 \mathrm{~g}$ of adsorbent was added into the solution under optimized conditions, at room temperature. The solutions were stirred for $30 \mathrm{~min}$ at $150 \mathrm{rpm}$ and allowed to settle. Finally, concentrations of all the above ions were measured using ion chromatography. The efficiency of the removal of soluble phosphate ions in a polluted water body was tested. Water samples of four randomly selected locations from Beira Lake (Colombo City Lake, Sri Lanka) were collected and transported to the laboratory by keeping in chilled conditions using ice. After that, 
TABLE 1: Conditions used in optimization studies.

\begin{tabular}{lcc}
\hline Optimizing parameters & Constant parameters \\
\hline Contact time (CT) & $5-120 \mathrm{~min}$ & $\mathrm{pH}-8$ \\
& & AD: $0.100 \mathrm{~g}$ \\
& & $\mathrm{IC}: 4 \mathrm{mg} / \mathrm{L}$ \\
\hline & & $\mathrm{pH}-8$ \\
Adsorbent dosage (AD) & $0.025-0.250 \mathrm{~g}$ & $\mathrm{CT}: 30 \mathrm{~min}$ \\
& & IC: $4 \mathrm{mg} / \mathrm{L}$ \\
\hline & & $\mathrm{AD}: 0.150 \mathrm{~g}$ \\
$\mathrm{pH}$ & $5-12$ & $\mathrm{CT}: 3 \mathrm{~min}$ \\
& & $\mathrm{IC}: 4 \mathrm{mg} / \mathrm{L}$ \\
\hline \multirow{2}{*}{$\begin{array}{l}\text { Initial concentration } \\
\text { (IC: ion chromatography) }\end{array}$} & $2-80 \mathrm{mg} / \mathrm{L}$ & $\mathrm{pH}-8$ \\
& & $\mathrm{AD}: 0.150 \mathrm{~g}$ \\
& &
\end{tabular}

$50.0 \mathrm{~mL}$ of collected water samples from each location was transferred into $100 \mathrm{~mL}$ beakers. Then, $0.15 \mathrm{~g}$ of synthesized nanoparticles was added into each sample and stirred for $30 \mathrm{~min}$ at $150 \mathrm{rpm}$ and allowed to settle. Finally, all the treated and untreated samples were analysed using ion chromatography to measure final phosphate concentrations.

\section{Results and Discussion}

3.1. Characterization of Synthesized Material. Figure 1 shows the DLS-based particle size distribution. It shows that the soft-templated method used in this work to synthesize the intended $\mathrm{CaCO}_{3}$ nanoparticles gives a very narrow and symmetrical size distribution within $20 \mathrm{~nm}$ to $30 \mathrm{~nm}$ size range, with the average particle size of $25.5 \mathrm{~nm}$ in the $90 \%$ confidence interval. This suggests that the colloidal solution prepared for size determination may have discrete particles which in turn suggests that the method gives nonaggregated nanoparticles or even if they are aggregated, they can be separated in solution simply by mechanical agitation. $\mathrm{CaCO}_{3}$ nanoparticles are grown in a soft molecular template consisting of a hydrogen-bonded network of supplemental ethylene glycol molecules and less amount of water molecules forming cavities for particles to nucleate and grow [21]. It seems that these cavities are in the size range of $20-30 \mathrm{~nm}$ and are homogeneous in terms of their sizes.

Figure 2 shows the SEM images of $\mathrm{CaCO}_{3}$ nanoparticles (a) before and (b) after phosphate adsorption.

The SEM images clearly show spherical morphology of particles though they seem to be much larger than $25.5 \mathrm{~nm}$ average size observed from the DLS experiment and are about $100-200 \mathrm{~nm}$ in diameters. This suggests that when the particles are dried, they tend to agglomerate. The particles thus arranged to have a large surface area owing to their highly porous structure [21]. When $\mathrm{CaCO}_{3}$ particles are used to remove phosphate ions from aqueous solution, tiny crystal growth on the surface of the particles can be clearly observed in Figure 2(b). These tiny particles could be calcium phosphate or hydroxyapatite particles formed on the surface of $\mathrm{CaCO}_{3}$ particles by reacting them with phosphate ions as observed by Karageorgiou et al. when they used natural calcite for phosphate removal [31].

Figures 3(a) and 3(b), respectively, express the XRD patterns of synthesized nanoparticles before and after phosphate adsorption. They clearly show that there is no significant difference between two X-ray diffractograms as they show the same number of peaks corresponding to the same $2 \theta$ values but with different intensity distribution.

According to the literature, the main characteristic peaks of vaterite polymorph at $2 \theta$ of $20.96^{\circ}, 24.80^{\circ}, 26.96^{\circ}, 32.72^{\circ}$, $43.76^{\circ}, 48.96^{\circ}, 50.00^{\circ}$, and $55.52^{\circ}$ correspond to the (004), (110), (112), (114), (300), (304), (118), and (224) crystallographic planes, respectively, all of which can be clearly observed in both diffractograms [12]. This confirms that the synthesized nanoparticles are in the vaterite crystalline phase. The reason for the changes in peak intensities after adsorption might be due to the preferential growth of certain crystal planes during the adsorption process. However, the XRD analysis could not clearly detect hydroxyapatite or any calcium phosphate species on the VPPCC nanoparticles. This might be due to the partial and poor crystal growth of such species grown on the VPPCC nanoparticles. This phenomenon is somewhat similar to the process of crystal growth of aragonite in the presence of orthophosphate where the crystallization of calcium phosphate or hydroxyapatite was not able to detect through XRD [32]. It is also possible that the newly grown crystallites are also composed of $\mathrm{CaCO}_{3}$ rather than phosphates but phosphate ions may be present adsorbed to them and encapsulated within the pores of the nanoparticles.

The FT-IR spectra of the synthesized nanoparticles before and after phosphate adsorption are shown in Figures 4(a) and 4(b), respectively.

Figure 4, clearly shows that there is a significant difference between two FT-IR spectra of synthesized nanoparticles before (Figure 4(a)) and after (Figure 4(b)) the adsorption process. According to the characteristic IR absorption bands of carbonate, symmetric stretching, out-of-plane bending, doubly degenerated planar asymmetric stretching, and doubly degenerated planar bending vibrations are shown at $1080 \mathrm{~cm}^{-1}, 870 \mathrm{~cm}^{-1}, 1400 \mathrm{~cm}^{-1}$, and $700 \mathrm{~cm}^{-1}$, respectively $[33,34]$. The FTIR spectrum (Figure $4(\mathrm{a}))$ shows absorption bands at $743\left(v_{4}\right.$, in-plane bending vibration), $872\left(v_{2}\right.$, carbonate out-of-plane bending vibration), 1087 ( $v_{1}$, symmetric stretch), and $1423 \mathrm{~cm}^{-1}\left(v_{3}\right.$, asymmetric stretch) that confirm the presence of the VPPCC [35]. There are no absorption bands present at 700, 854, 873, and $2522 \mathrm{~cm}^{-1}$ corresponding to aragonite and 714 and $848 \mathrm{~cm}^{-1}$ corresponding calcite ([36, 37]. Therefore, the synthesized particles can be considered as a pure form of VPPCC nanoparticles before the adsorption of phosphate. The FT-IR spectrum of hydroxyapatite should have phosphate vibrations at $460 \mathrm{~cm}^{-1}\left(v_{2}\right), 560-600 \mathrm{~cm}^{-1}\left(v_{4}\right)$, $960 \mathrm{~cm}^{-1}\left(v_{1}\right), 10201120 \mathrm{~cm}^{-1}$, and $1040 \mathrm{~cm}^{-1}\left(v_{3}\right)([38,39]$. The FT-IR spectrum given in Figure 4(b) shows the presence of absorption bands at $567 \mathrm{~cm}^{-1}$ and $1040 \mathrm{~cm}^{-1}$ after the adsorption process, which is corresponding to the phosphate while showing bands corresponding to the hydroxyl groups $\left(1652 \mathrm{~cm}^{-1}, 3420 \mathrm{~cm}^{-1}\right)$ and adsorbed water $\left(2930 \mathrm{~cm}^{-1}\right)$ [27]. 


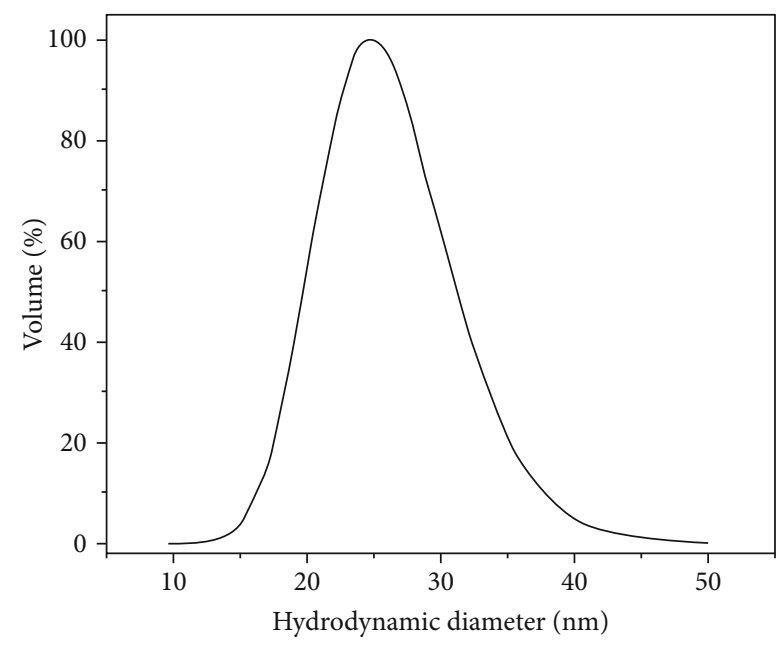

FIGURE 1: Size distribution of nanoparticles measured from dynamic laser light scattering.

Therefore, it proves the formation of hydroxyapatite species on the nanoparticle after phosphate adsorption onto the VPPCC nanoparticles ([38]: [27]).

EDAX analysis and corresponding elemental distribution maps are given in Figure 5 (a1, a2, and a3) which shows that there are only carbon, calcium, and oxygen present before the adsorption of phosphate. The carbon percentage detected is somewhat higher than the expected theoretical percentage due to the detection of carbon available in the double-sided conductive adhesive carbon tabs and tapes used. Figure 5 (b1, b2, b3, and b4) clearly shows the availability of a small amount of phosphorus and sodium apart from elements detected for the same material before adsorption. The reason for less amount of phosphorus availability might be due to the considerable amount of phosphate ions that have been adsorbed into the inside of the porous nanoparticles, but EDAX identifies only the phosphorus adsorbed onto the surface. Detection of sodium is due to the adsorption of sodium ions that were available in the phosphate solution in the trisodium phosphate used.

3.2. Batch Adsorption Study. In order to optimize conditions used, the phosphate removal was studied as a function of contact time, VPPCC nanoparticle dosage, $\mathrm{pH}$ of the medium, and initial phosphate ion concentration used and the results are depicted in Figures 6(a)-6(d), respectively.

Figure 6(a) shows that the phosphate removal percentage has been increased from $1 \mathrm{~min}$ to $30 \mathrm{~min}$ and reached a constant value of $\sim 75 \%$ after $30 \mathrm{~min}$ of shaking time. As the adsorption proceeds, the active site concentration decreases due to the filling of all adsorption sites with the adsorbate species and eventually all the sites get saturated. Under the conditions used, $75 \%$ of phosphate ions from $50.0 \mathrm{~mL}$ of $4 \mathrm{mg} / \mathrm{L}$ solution have been adsorbed by $0.100 \mathrm{~g}$ of VPPCC nanoparticles at $\mathrm{pH} 8$. Therefore, $30 \mathrm{~min}$ shaking time was taken as the optimum contact time. Figure 6(b) shows that increasing the adsorbent dosage from $0.025 \mathrm{~g}$ to $0.200 \mathrm{~g}$, the phosphate removal percentage increases from $25 \%$ to $100 \%$ at the optimized $30 \mathrm{~min}$ contact time. But the $0.150 \mathrm{~g}$ was taken as the optimum dosage as it is the closest dosage to the $0.200 \mathrm{~g}$ which shows $100 \%$ removal of phosphate, to optimize the other conditions. Figure 6(c) shows that the phosphate adsorption by VPPCC nanoparticles is weakly $\mathrm{pH}$ dependent in weakly acidic and neutral $\mathrm{pH}$ conditions. When the solution is made basic, adsorption increases and shows $100 \%$ adsorption at $\mathrm{pH} 12$. This is because at acidic $\mathrm{pH}$ values, phosphate ions get protonated and the ability to form coordination bonds with calcium ions becomes less. As $\mathrm{pH}$ is raised, those acidic groups get ionized, and at $\mathrm{pH} 12$, phosphate ion is present as $\mathrm{PO}_{4}{ }^{3-}$ making it highly favorable for coordination with calcium ions. The same trend of phosphate adsorption on calcite was reported by Meejoo et al. [40] though higher $\mathrm{pH}$ values are more favorable for vaterite than for calcite [41]. When comes to practical situations, however, high $\mathrm{pH}$ values around 10-12 $\mathrm{pH}$ are not suitable since another chemical must be added to the water to increase the $\mathrm{pH}$. Therefore, the neutral $\mathrm{pH}$ values 7-8 can be used to remove phosphate ions in water using VPPCC nanoparticles since $80-85 \%$ of phosphate removal can be obtained under these conditions.

Moreover, the $\mathrm{pH}$ change during the treatment process was examined and results are depicted in Figure 6(e). It clearly shows that there is no significant change during the treatment process as the $\mathrm{pH}$ is remaining between 8.01 and 8.31. This might be due to a number of reasons. First, the solubility of the calcium carbonate is around $0.001 \mathrm{mg} / \mathrm{L}$ at $\mathrm{pH} 8$ which was used as the optimum $\mathrm{pH}$ in the phosphate solution for the treatment. Therefore, the solubility of vaterite may be very low during the treatment. Second, there is no change in the temperature during the treatment and the vaterite structure gets more stable with the adsorption of phosphate ions. However, the $\mathrm{pH}$ of the final solution is remaining after the treatment despite the reactions that occurred during the treatment.

The effect of initial phosphate concentration on phosphate removal is shown in Figure 6(d). The maximum phosphate removal percentage of $100 \%$ can be observed at the $2 \mathrm{mg} / \mathrm{L}$ phosphate solution, and the phosphate removal percentage decreases as the initial concentration is increased. This might be due to the fact that, at higher phosphate concentrations, the binding capacity of the VPPCC nanoparticle reaches saturation, resulting in a decrease of overall phosphate removal percentage. Therefore, the $2 \mathrm{mg} / \mathrm{L}$ was selected as the optimum concentration of phosphate under all other optimized conditions. Original raw data and statistically analysed original data have been given in supplementary materials from Tables S01 to S05 and Tables S08 to S12, respectively.

3.3. Kinetic Studies. Heterogeneous kinetics of adsorption of solution species on solid surfaces usually follows pseudofirst-order proposed by Lagergren or pseudo-second-order kinetics and the linearized form of pseudo-first-order is given in Equation (1) [42, 43].

$$
\log \left(q_{e}-q_{t}\right)=\log q_{e}-\frac{K_{1 p}}{2.303} t
$$




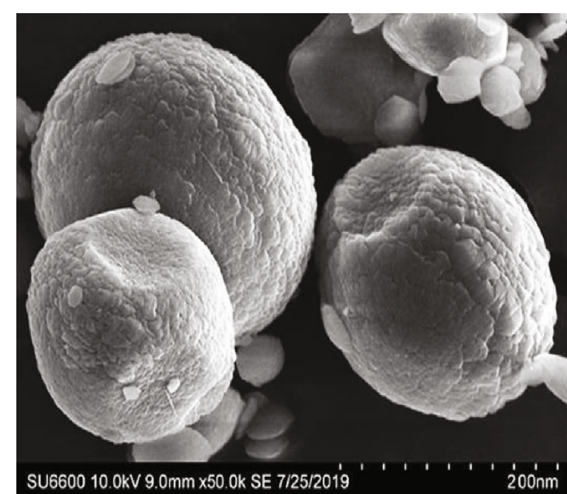

(a)

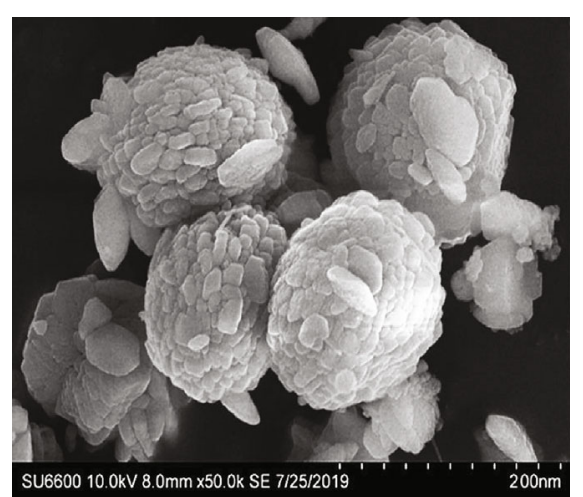

(b)

Figure 2: SEM images of $\mathrm{CaCO}_{3}$ particles (a) before phosphate adsorption (b) after phosphate adsorption.

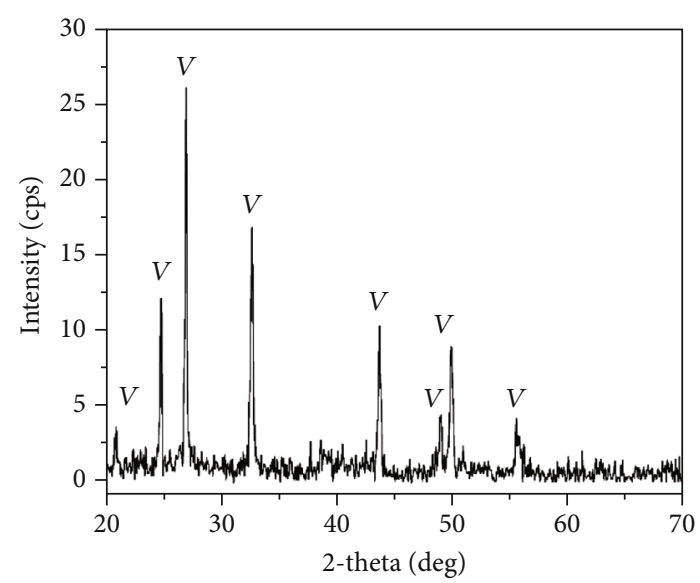

(a)

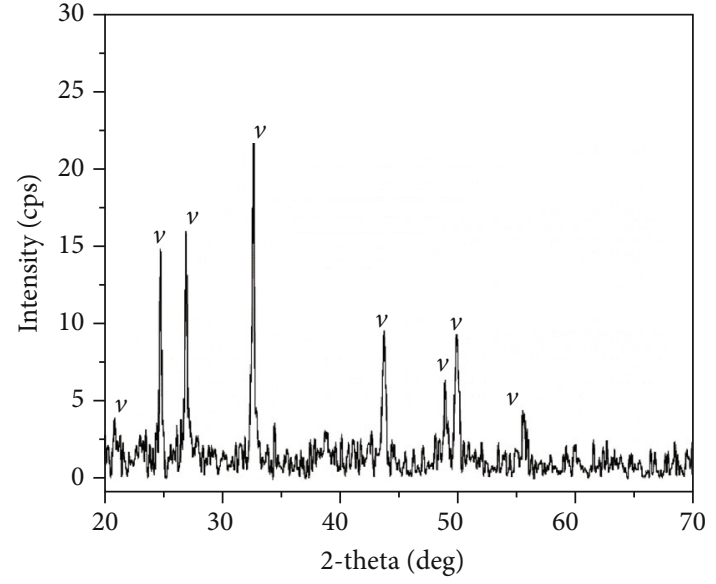

(b)

FIGURE 3: XRD analysis of the synthesized nanoparticles (a) before and (b) after phosphate adsorption.

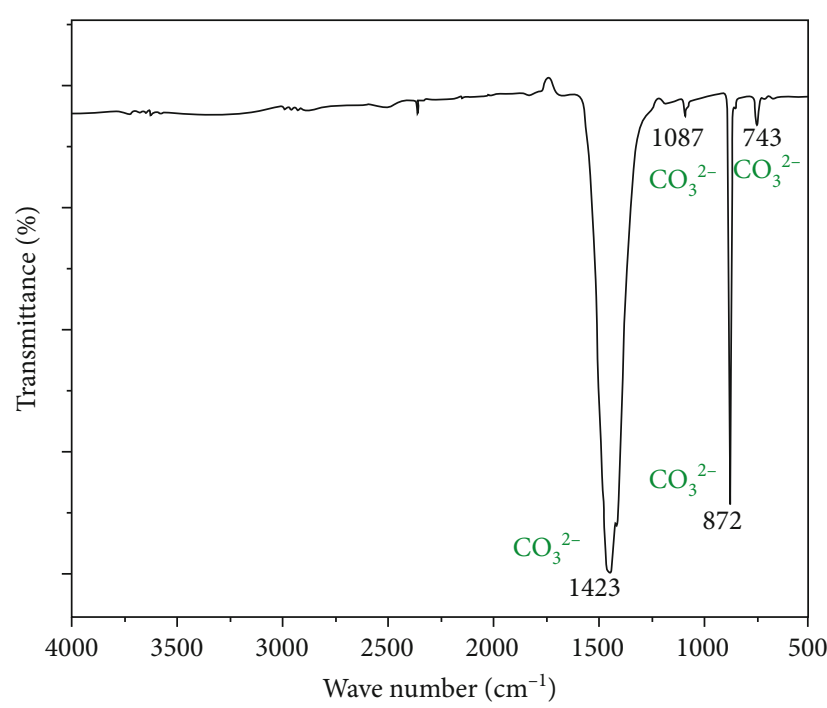

(a)

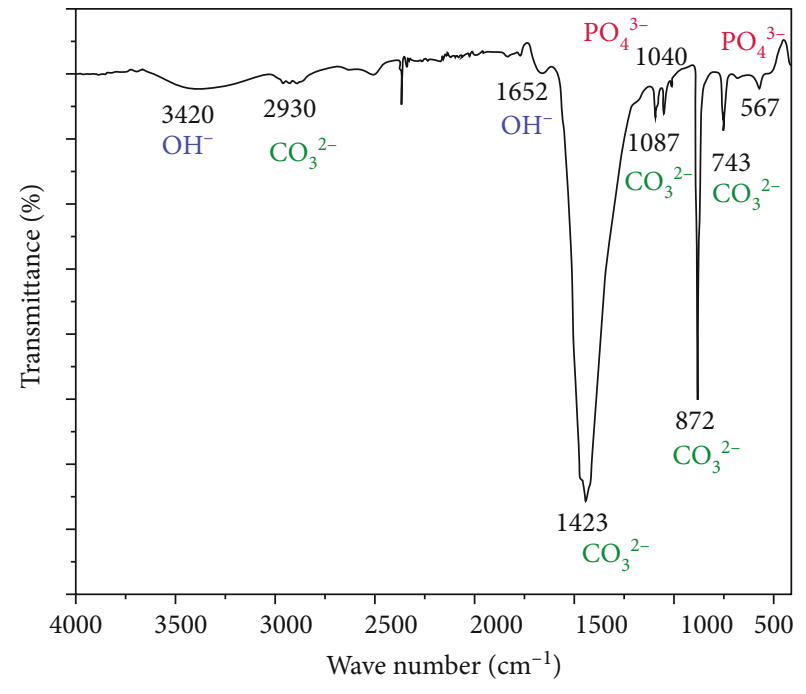

(b)

FIGURE 4: FT-IR spectrum of VPPCC nanoparticles (a) before phosphate adsorption (b) after phosphate adsorption. 

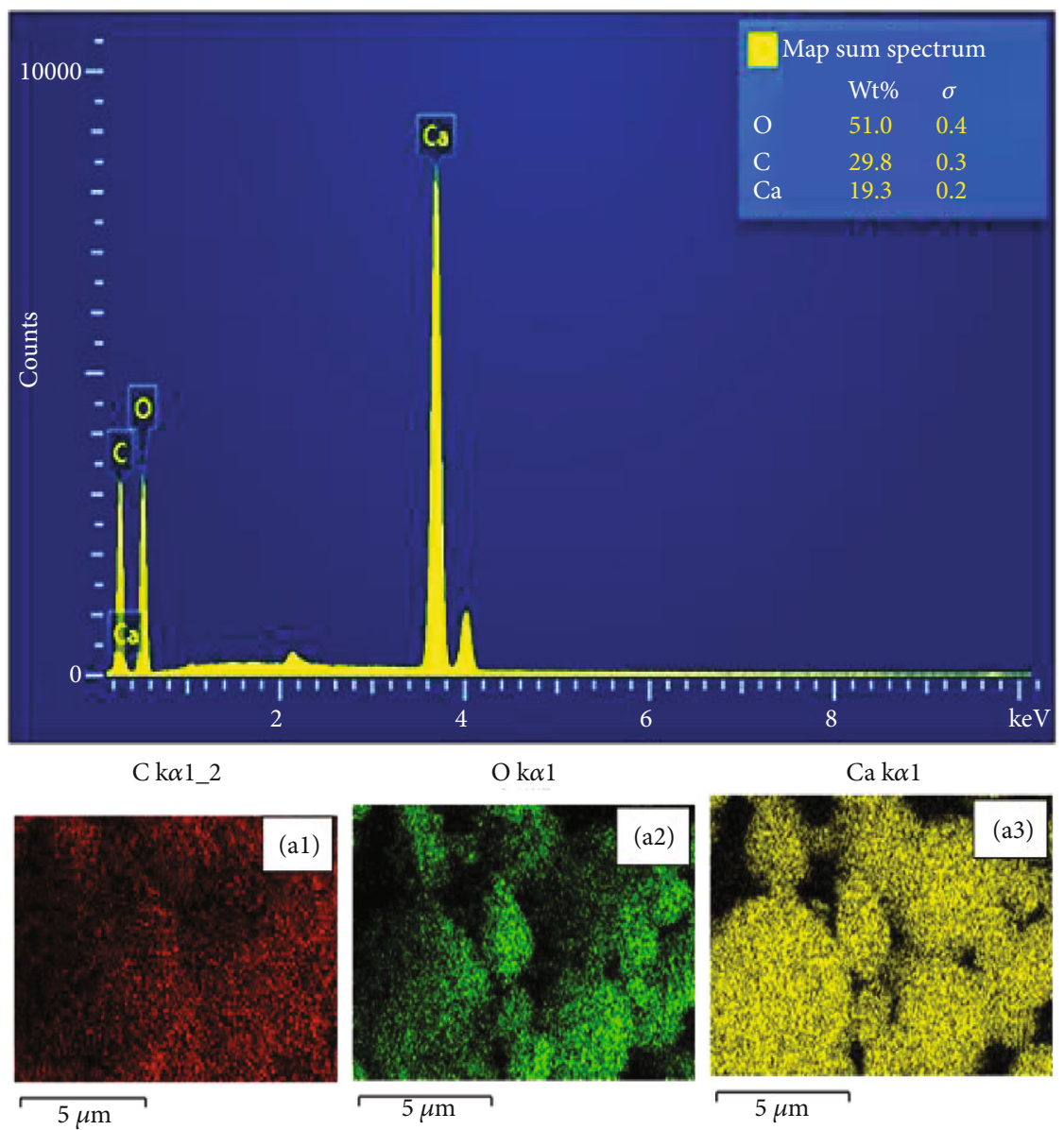

(a)

Figure 5: Continued. 


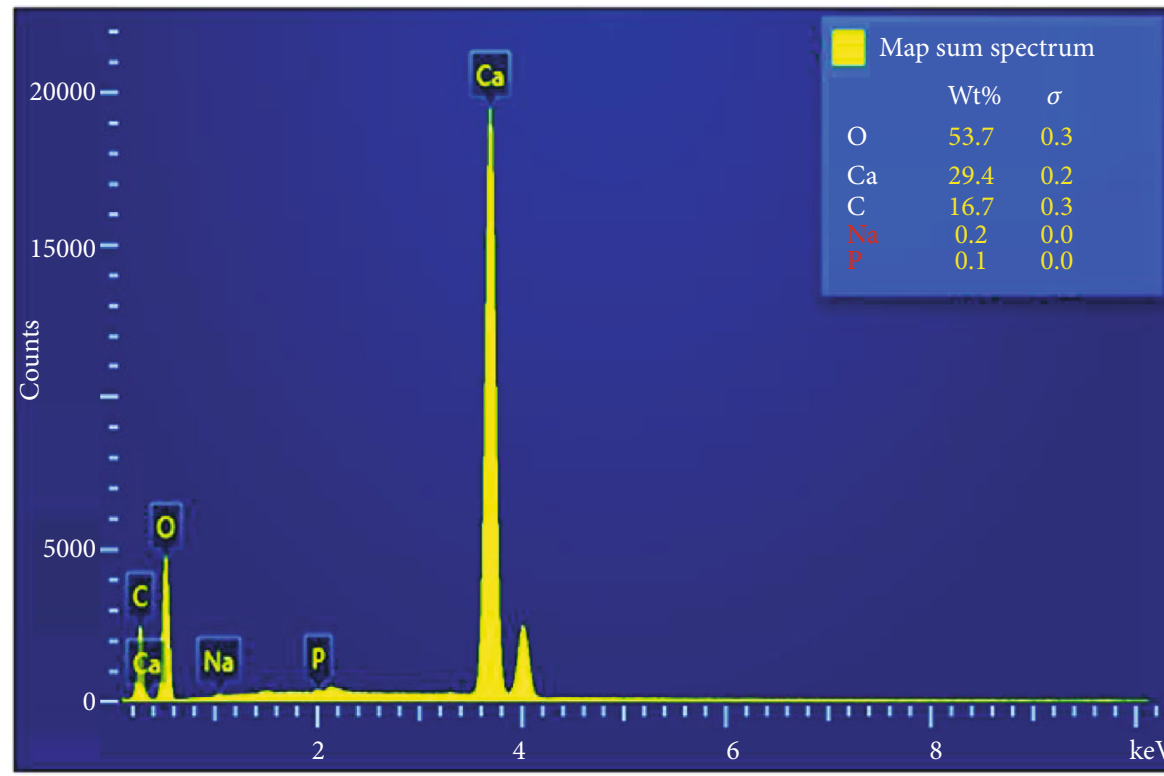

$\mathrm{P} k \alpha 1$

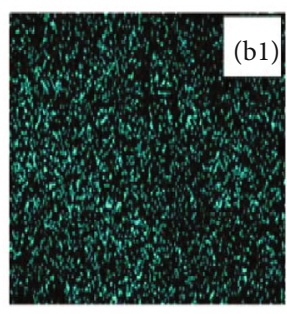

$5 \mu \mathrm{m}$
C k $\alpha 1 \_2$

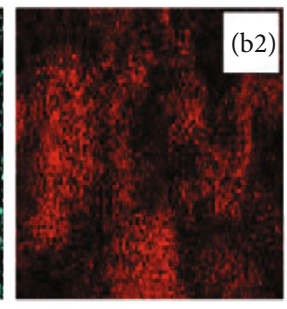

$5 \mu \mathrm{m}$
$\mathrm{O} k \alpha 1$

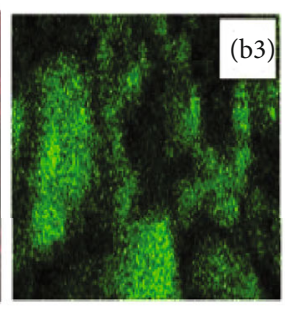

$5 \mu \mathrm{m}$
Ca k $\alpha 1$

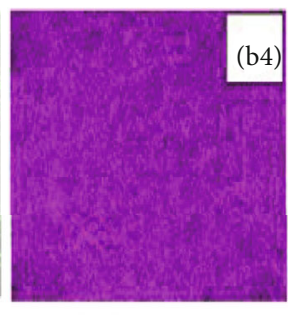

$5 \mu \mathrm{m}$

(b)

FIGURE 5: EDAX spectrum and X-ray elemental distribution maps of VPPCC nanoparticles (a) before adsorption: (a1) carbon, (a2) oxygen, and (a3) calcium, and (b) after adsorption: (b1) phosphorus (b2), carbon (b3), oxygen, and (b4) calcium.

The linearized form of the pseudo-second-order expression is given in

$$
\frac{t}{q_{t}}=\frac{1}{K_{2 p} q_{e}^{2}}+\frac{1}{q_{e}} t .
$$

Here, $q_{t}$ and $q_{e}$ are considered as the amount of solute adsorbed per mass of sorbent $\left(\mathrm{mgg}^{-1}\right)$ at any time $(t)$ and equilibrium (e), respectively, $K_{1} p$ is the rate constant of the pseudo-first-order adsorption (1/min), and $K_{2} p$ is the rate constant of the $\left(\mathrm{gg}^{-1} \mathrm{~min}^{-1}\right)$ pseudo-second-order adsorption.

According to the kinetic results, shown in Figure 7, the data fits reasonably well with the pseudo-second-order kinetic model which shows a 0.98 of $R^{2}$ value. This suggests that the rate depends on both the phosphate concentration and the concentration of adsorption sites on the surface of the VPPCC nanoparticles. Thus, the adsorption process of phosphate ions onto the VPPCC nanoparticle happens through the formation of covalent bonds between the adsorbent and adsorbate through chemisorption (Table 2) [42, 44]. The original data for kinetic studies with statistical analysis have been given in Table S06 in the supplementary data sheet.

\subsection{Isotherm Studies}

3.4.1. Linear Forms of the Isotherm Models. Linear forms of the isotherm models are also widely adopted to determine the isotherm parameters or the most fitted model for the adsorption system due to the mathematical simplicity. The Langmuir isotherm model assumes that the adsorption is occurring as a homogeneous monolayer adsorption onto a surface containing a limited number of adsorption sites of uniform strategies; adsorbed molecules do not interact with no transmigration of adsorbate in the plane adsorbent surface [44].

The linear form of the Langmuir isotherm model can be expressed as

$$
\frac{C_{e}}{q_{e}}=\frac{1}{q_{m}} C_{e}+\frac{1}{K_{L} q_{m}},
$$

where $q_{e}, q_{m}, C_{e}$, and $K_{L}$ are the corresponding adsorption capacity $(\mathrm{mg} / \mathrm{g})$, maximum adsorption capacity $(\mathrm{mg} / \mathrm{g})$, 


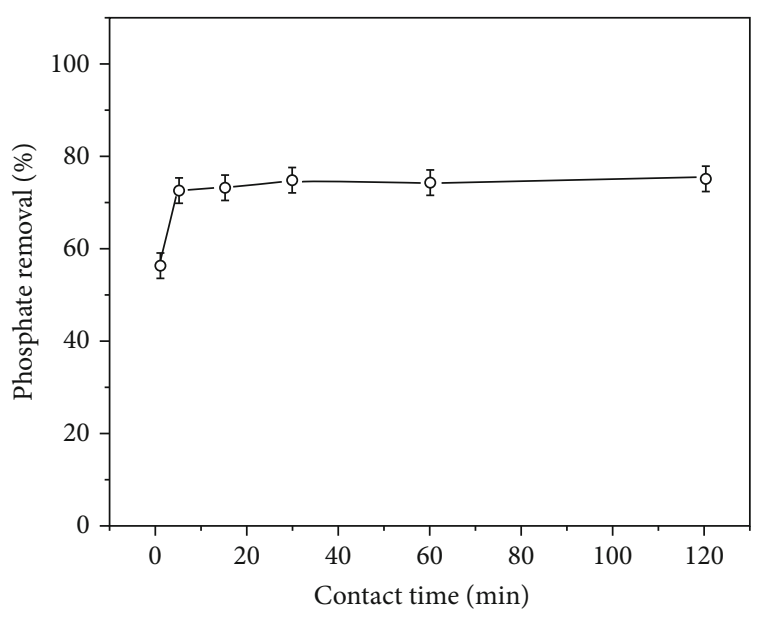

(a)

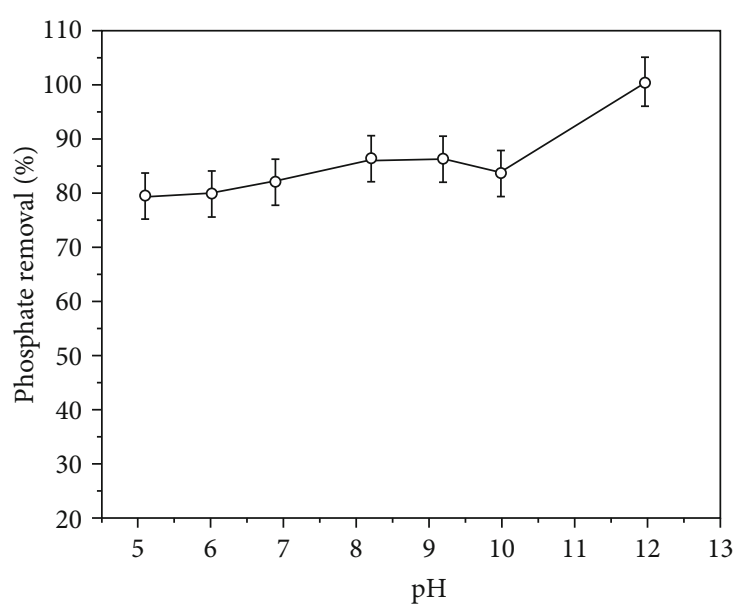

(c)

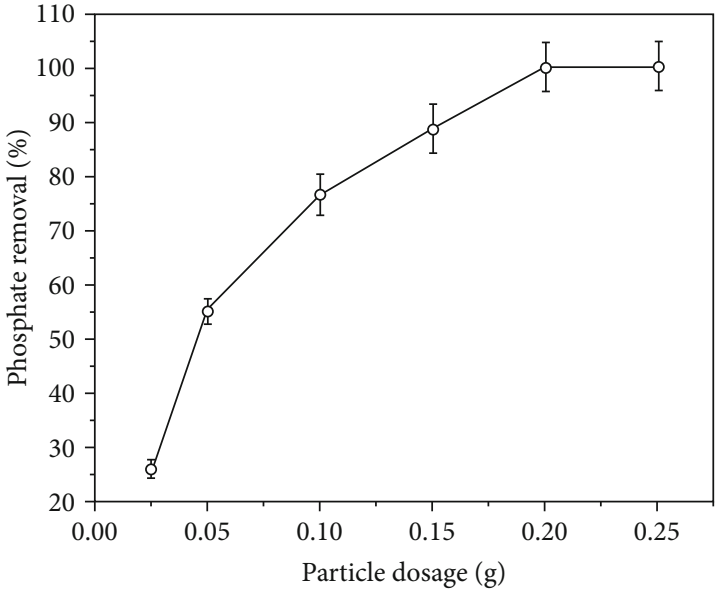

(b)

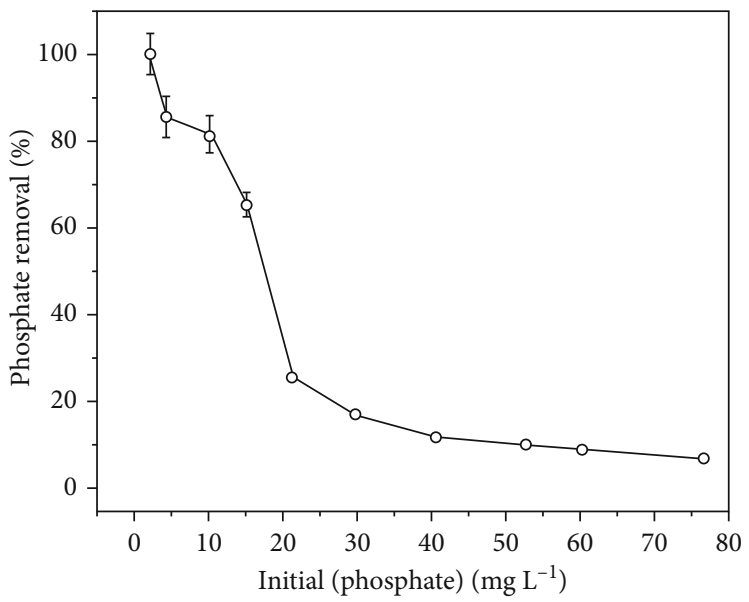

(d)

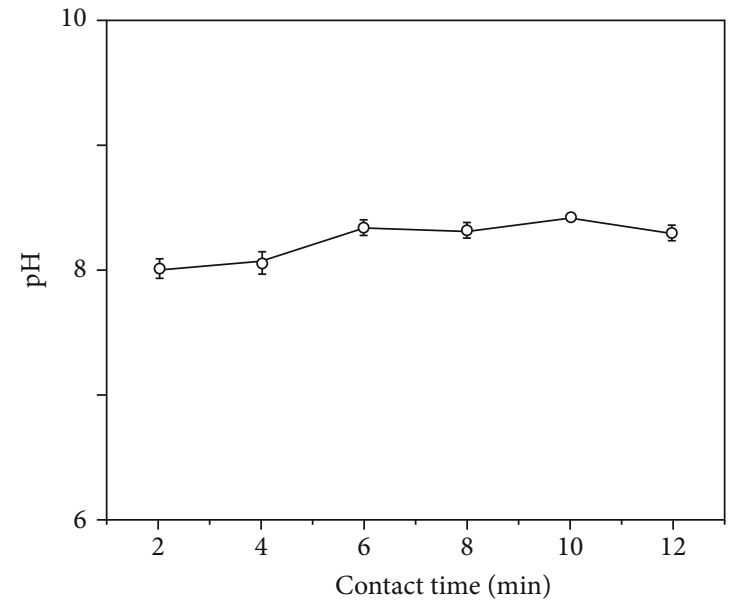

(e)

Figure 6: Phosphate removal percentages at different (a) contact times (min), (b) particle dosages, (c) pH levels, and (d) initial phosphate concentrations $(\mathrm{mg} / \mathrm{L})$ and $(\mathrm{e}) \mathrm{pH}$ change during the treatment. 


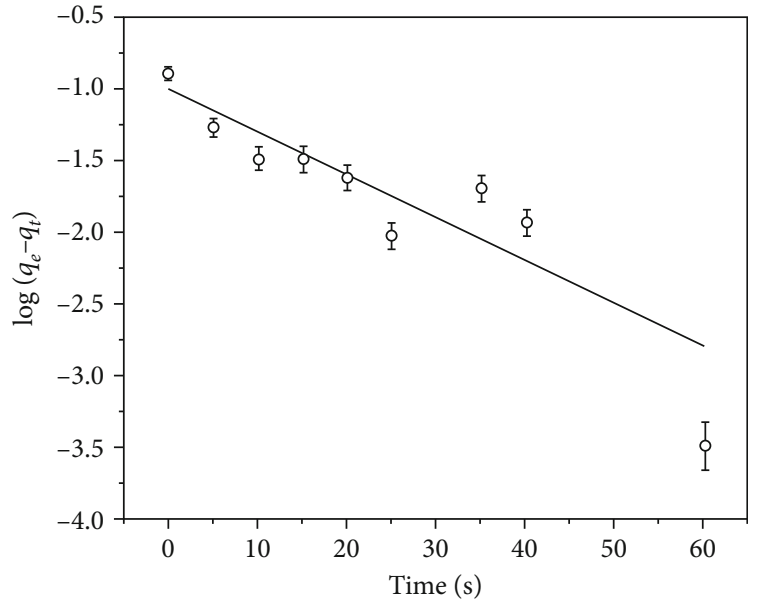

(a)

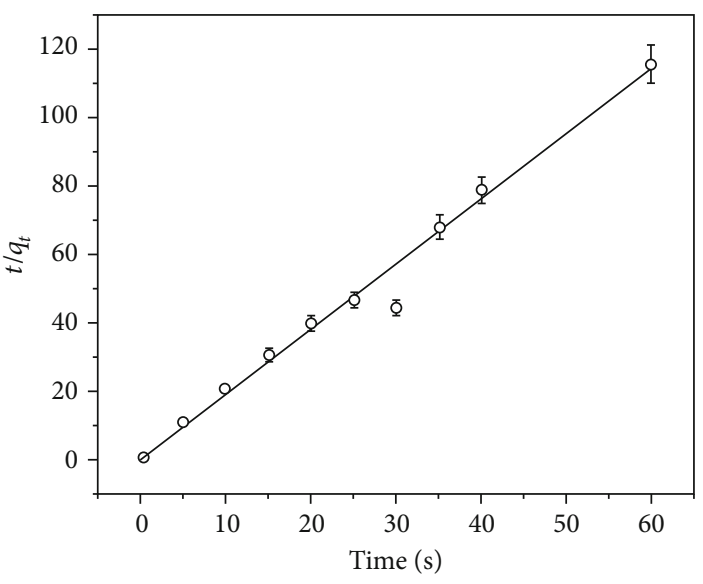

(b)

FIGURE 7: Adsorption kinetic study of phosphate adsorption on VPPCC nanoparticles (a) pseudo-first-order kinetic model and (b) pseudosecond-order kinetic model.

TABLE 2: The kinetic parameters obtained using pseudo-first-order and pseudo-second-order rate laws at room temperature for the adsorption of phosphate on VPPCC nanoparticles.

\begin{tabular}{lcccc}
\hline Kinetic model & $R^{2 \text { ab }}$ & $\begin{array}{c}\text { Rate } \\
\text { constant }\end{array}$ & $\begin{array}{c}\text { Value of rate } \\
\text { constant }\end{array}$ & $\begin{array}{c}\text { Units of rate } \\
\text { constant }\end{array}$ \\
\hline $\begin{array}{l}\text { Pseudo-first- } \\
\text { order }\end{array}$ & 0.81 & $k_{1 p}$ & 0.080 & $\mathrm{~min}^{-1}$ \\
\hline $\begin{array}{l}\text { Pseudo- } \\
\text { second-order }\end{array}$ & 0.98 & $k_{2 p}$ & 0.083 & $\mathrm{gg}^{-1} \mathrm{~min}^{-1}$ \\
\hline
\end{tabular}

${ }^{\mathrm{a}} R^{2}$ : regression coefficient. Note: $\mathrm{g}^{-1}$ refers to the adsorbate and $\mathrm{g}$ refers to the adsorbent. ${ }^{\mathrm{b}}$ The $k_{1 p}$ and $k_{2 p}$ values and the nonlinear regression correlations for pseudo-first-order and pseudo-second-order were measured by nonlinear regression analysis using Origin Pro 8.0.

equilibrium concentration $(\mathrm{mg} / \mathrm{L})$, and adsorption equilibrium constant called the Langmuir constant $(\mathrm{L} / \mathrm{mg})$ [45].

The Freundlich isotherm model describes that the adsorption is a multilayer heterogeneous adsorption and its linear form can be expressed as

$$
\log q_{e}=\log K_{F}+\frac{1}{n} \log C_{e}
$$

where $K_{F}, n, C_{e}$, and $q_{e}$ are the Freundlich constant (mg/g), a constant, equilibrium concentration $(\mathrm{mg} / \mathrm{L})$, and corresponding adsorption capacity $(\mathrm{mg} / \mathrm{g})$, respectively.

3.4.2. Nonlinear Forms of the Isotherm Models. The nonlinear expression of the Langmuir isotherm model can be illustrated as

$$
q_{e}=q_{m} K_{L} \frac{C_{e}}{1+K_{L} C_{e}}
$$

where $q_{e}, q_{m}, C_{e}$, and $K_{L}$ are the corresponding adsorption capacity $(\mathrm{mg} / \mathrm{g})(\mathrm{mg} / \mathrm{L})^{-1 / n}$, maximum adsorption capacity $(\mathrm{mg} / \mathrm{g})$, equilibrium concentration $(\mathrm{mg} / \mathrm{L})$, and adsorption equilibrium constant called the Langmuir constant $(\mathrm{L} / \mathrm{mg})$ [45].

The nonlinear expression of the Freundlich isotherm model can be illustrated as

$$
q_{e}=K_{F} C_{e}^{1 / n}
$$

where $K_{F}, n, C_{e}$, and $q_{e}$ are the Freundlich constant $(\mathrm{mg} / \mathrm{g})^{(1-}$ ${ }^{1 / n)}$, a constant, equilibrium concentration (mg/L), and corresponding adsorption capacity $(\mathrm{mg} / \mathrm{g})$, respectively.

The data fitted to the linear expressions of adsorption isotherms and nonlinear expressions of adsorption isotherms are shown in Figures 8 and 9, respectively. Figure 8(a) clearly shows the linear behavior expected for the Langmuir adsorption isotherm though the data fitted to the Freundlich adsorption isotherm show highly scatted nature (Figure 8(b)). This suggests that the adsorption of phosphate on vaterite nanoparticles occurs only to monolayer coverage influenced by strong chemical interactions. The data points of the nonlinear Langmuir adsorption isotherm also fit well with the expected curve but the same for the Freundlich isotherm show scattered nature.

Table 3 collects the adsorption parameters of the Langmuir and Freundlich isotherms at room temperature for the adsorption of phosphate on VPPCC nanoparticles. Original data with the statistical analysis has been given in the supplementary data sheet (Table S07).

According to Table 3, the Langmuir isotherm model fits well with both the linear and nonlinear forms of the Langmuir isotherm model $\left(R^{2}=0.99\right.$ and $R^{2}=0.95$, respectively). Meanwhile, the standard errors (S:E) and root mean square error (RMSE) for most of the parameters in the Freundlich isotherm model are comparatively higher than the Langmuir isotherm model [46]. This suggests the Langmuir isotherm model can generate a satisfactory fit to the data than Freundlich. Therefore, it can be concluded that the adsorption of phosphate ions on VPPCC nanoparticles is a homogeneous 


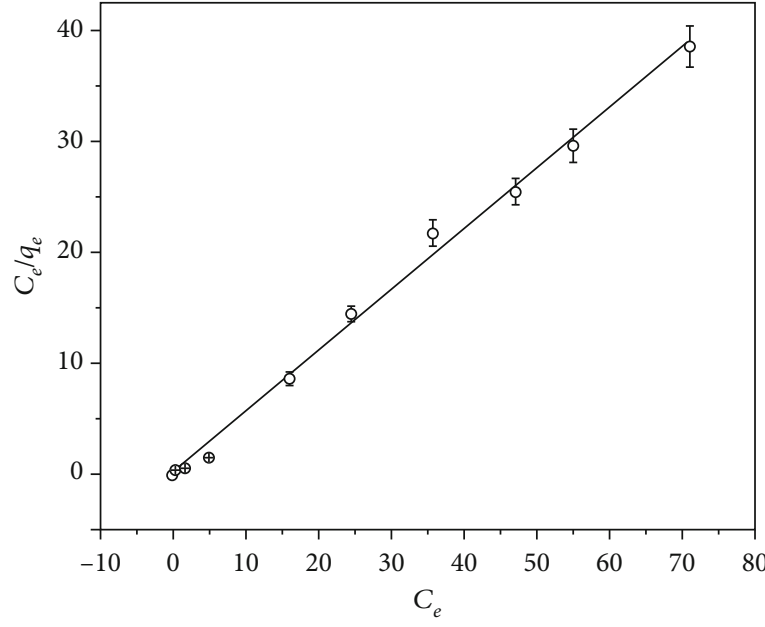

(a)

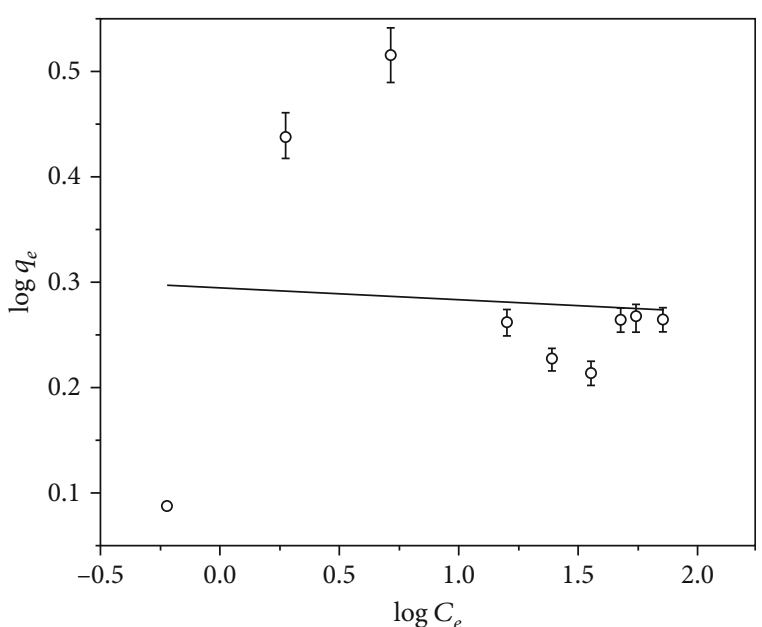

(b)

FIGURE 8: Adsorption isotherm study on VPPCC nanoparticle: (a) Langmuir isotherm model and (b) Freundlich isotherm model.

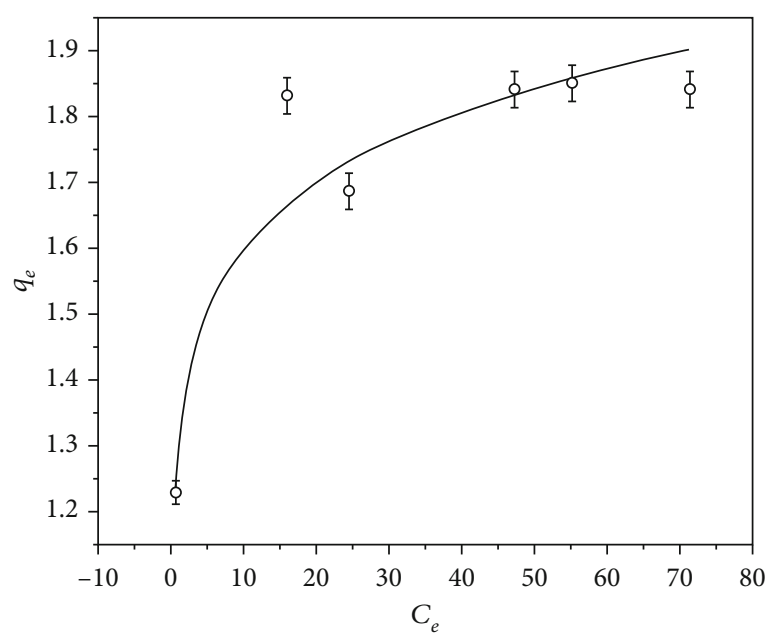

(a)

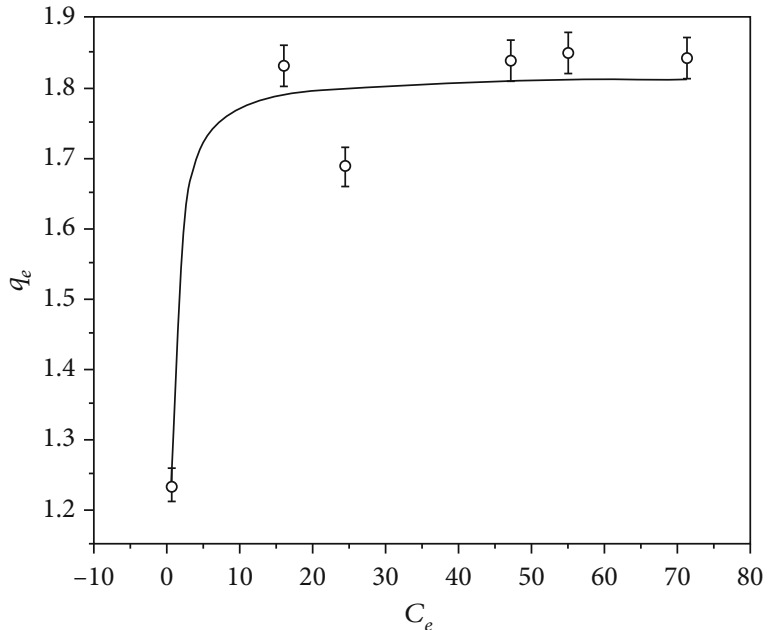

(b)

Figure 9: Adsorption isotherm study on VPPCC nanoparticle: (a) nonlinear Langmuir isotherm model and (b) nonlinear Freundlich isotherm model.

TABLE 3: Adsorption parameters of the Langmuir and Freundlich isotherms at room temperature for the adsorption of phosphate on VPPCC nanoparticles.

\begin{tabular}{|c|c|c|c|c|c|c|c|}
\hline \multirow{2}{*}{\multicolumn{2}{|c|}{ Model/parameters }} & \multicolumn{3}{|c|}{ Linear expression } & \multicolumn{3}{|c|}{ Nonlinear expression } \\
\hline & & Value & Standard error & Root mean square error & Value & Standard error & Root mean square error \\
\hline \multirow{3}{*}{ Langmuir } & $q_{m}(\mathrm{mg} / \mathrm{g})$ & 1.87 & 0.017 & \multirow{3}{*}{1.015} & 1.82 & 0.031 & \multirow{3}{*}{2.588} \\
\hline & $K_{L}(\mathrm{~L} / \mathrm{mg})$ & 0.70 & 0.024 & & 3.45 & 0.609 & \\
\hline & $R^{2}$ & 0.99 & - & & 0.95 & - & \\
\hline \multirow{4}{*}{ Freundlich } & $K_{F}(\mathrm{mg} / \mathrm{g})(\mathrm{mg} / \mathrm{L})^{-1 / n}$ & 1.31 & 0.022 & \multirow{4}{*}{0.026} & 1.31 & 0.076 & \multirow{4}{*}{3.333} \\
\hline & $n$ & 11.88 & 0.015 & & 11.44 & 2.353 & \\
\hline & $1 / n$ & 0.08 & - & & 0.09 & - & \\
\hline & $R^{2}$ & 0.84 & - & & 0.92 & - & \\
\hline
\end{tabular}


TABLE 4: Adsorption capacities of other materials used by other researchers.

\begin{tabular}{lcc}
\hline Material & Absorption capacity $\left(q_{m}\right)$ & Reference \\
\hline Activated carbon-silica nanoparticle composite & $0.65 \mathrm{mg} / \mathrm{g}$ & {$[50]$} \\
Titanium oxide nanoparticles & $0.77 \mathrm{mg} / \mathrm{g}$ & {$[28]$} \\
Red mud (with acid and acid-thermal treatments) & $0.58 \mathrm{mg} / \mathrm{g}$ & $8.70 \mathrm{mg} / \mathrm{g}$ \\
Phosphate mine wastes & $13.62 \mathrm{mg} / \mathrm{g}$ & $151]$ \\
Silver nanoparticle-loaded activated carbon derived from tea residue & $18.69 \mathrm{mg} / \mathrm{g}$ & {$[52]$} \\
Iron oxide nanoparticles synthesized by eucalyptus leaf extract & $1.87 \mathrm{mg} / \mathrm{g}$ & {$[53]$} \\
in the presence of CTAB surfactant & Present research \\
Vaterite polymorph of porous calcium carbonate nanoparticles &
\end{tabular}

monolayer coverage. Additionally, the " $1 / n$ " value of the Freundlich isotherm shows that the process is a chemisorption as it is less than one (Table 3 ), since it is considered $1 /$ $n$ value below one implies the chemisorption process and $1 /$ $n$ greater than one is an indication of cooperative adsorption [47]. The essential features of the Langmuir adsorption isotherm parameters can be used to predict the affinity between the sorbate and sorbent using a dimensionless constant or the separation factor.

According to McKay et al., the effect of isotherm shape has been considered by Weber and Chakra orti, with a view to predicting if an adsorption system is "favorable" or "unfavorable." There they considered essential features of the Langmuir isotherm which can be expressed in terms of a dimensionless constant separation factor " $r$ " as defined in

$$
r=\frac{1}{\left(1+b C_{0}\right)},
$$

where $C_{0}$ is the initial concentration $(\mathrm{mg} / \mathrm{L})$ and $b$ is a constant with units of $\mathrm{L} / \mathrm{mg}$ [47]. The calculated $r$ values for the linear and nonlinear Langmuir isotherm models are 0.20 and 0.0 , respectively.

Since the calculated $r$ values are between 0 and 1 , the adsorption process of phosphate ions on VPPCC nanoparticles can be considered as a favorable adsorption since the value of $r$ indicates the type of Langmuir isotherm to be irreversible ( $r=0, b$ is reaching infinity), linear $(r=1$ when $b=0$ ), unfavorable $(r>1$, when $b$ is negative), or favorable $(0<r<1)$ [48].

Table 4 depicts the adsorption capacities $\left(q_{m}\right)$ of some materials recently studied for phosphate removal. Although some of the materials like immobilized nanosized magnetite layer, iron oxide nanoparticles, lignin-based nanoadsorbent, and silver nanoparticles show somewhat higher adsorption capacities, it is clear that those metal-based nanomaterials cannot be used in a large scale as the synthesis methods are complex and the iron oxide nanoparticles can be bioaccumulated in aquatic animal bodies causing histopathology anomalies in both gills and intestine [49]. On the other hand, lowcost nanomaterials like titanium oxide, activated carbonsilica nanocomposite, and red mud show comparatively lower adsorption capacities than VPPCC nanoparticles.

3.5. Effects of Other Ions Present in Water. Sulphate, nitrate, and fluoride were taken as anions to test the effects of other ions for the phosphate removal using VPPCC nanoparticles as those are the ions commonly available in the wastewaters [54]. According to the data given in Table 5, there is no significant effect of these anions to the adsorption of phosphate ions onto the vaterite. This means that the nanoparticles can adsorb phosphate ions selectively from the mixture of anions. This might be due to its high charge $\left(\mathrm{PO}_{4}^{3-}\right)$ helping to strongly attract towards the calcium ions in the vaterite. Additionally, phosphate ion is capable of making strong dative bonding with $\mathrm{Ca}^{2+}$ sites whereas the dative bonding capacity of nitrate, sulphate, and fluorides is much weaker. However, the data also indicate that the particles have adsorbed some amount of fluoride ions. But there is no significant effect for the phosphate adsorption process due to its rapid adsorption nature. According to the data given in three columns, the concentrations of nitrate and sulphate have been increased after the treatment process with the nanoparticle. This is because when dry powder of nanoparticles is added to the aqueous solution, a considerable amount of water molecules is taken into the porous structures of the particle thus making the solution in contact with particles more concentrated than the original solution. This is an added evidence to show that the vaterite nanoparticles produced in this work are highly porous and a significant amount of water uptake is achieved at the point of incipient wetness.

3.6. Natural Water Sample Treatment. Table 6 gives the phosphate removal behavior of natural water samples collected from different locations of the waterbody as detailed in the experimental section and subjected to a pretreatment.

According to these data, when the water samples are filtered through a vacuum filter or with a pretreatment, phosphate ions can be removed at $100 \%$ efficiency under the optimized conditions used in the batch adsorption study. In the water treatment industry, these nanoparticles can be used in a filtering system at both the input and the output of the industrial effluents to remove phosphate ions. It prevents the excess algae growth both inside and outside of the waterbody. Also, it is possible to use these particles directly in the small earthen ponds or tanks without any filtering system because the particles can be collected when the pond or tank is cleaned after a certain period. Therefore, the frequency of water exchange in such ponds and tanks can be reduced as water quality degradation caused by algal growth is prevented. Alternatively, a certain level of algae growth can be 
TABLE 5: Removal of other anions at a concentration (A) as same as the phosphate concentration, (B) lower than the phosphate concentration, and $(\mathrm{C})$ higher than the phosphate concentration.

\begin{tabular}{lccccccccc}
\hline \multirow{2}{*}{ Anion } & \multicolumn{3}{c}{ Initial concentration $(\mathrm{mg} / \mathrm{L})$} & \multicolumn{3}{c}{ Final concentration $(\mathrm{mg} / \mathrm{L})$} & \multicolumn{3}{c}{ Removal (\%) } \\
& $\mathrm{A}$ & $\mathrm{B}$ & $\mathrm{C}$ & $\mathrm{A}$ & $\mathrm{B}$ & $\mathrm{C}$ & $\mathrm{A}$ & $\mathrm{B}$ & $\mathrm{C}$ \\
\hline Fluoride & 0.789 & 4.434 & 1.756 & 0.533 & 3.439 & 1.247 & $32 \%$ & $22 \%$ & $29 \%$ \\
Nitrate & 0.867 & 4.872 & 1.864 & 0.940 & 4.970 & 2.033 & $\mathrm{C} / \mathrm{I}$ & $\mathrm{C} / \mathrm{I}$ & $\mathrm{C} / \mathrm{I}$ \\
Phosphate & 2.001 & 2.115 & 2.054 & 0.000 & 0.000 & 0.000 & $100 \%$ & $100 \%$ & $100 \%$ \\
Sulphate & 0.826 & 4.593 & 1.824 & 1.088 & 4.721 & 2.104 & $\mathrm{C} / \mathrm{I}$ & $\mathrm{C} / \mathrm{I}$ & $\mathrm{C} / \mathrm{I}$ \\
\hline
\end{tabular}

C/I: concentration increased.

TABLE 6: Phosphate removal behavior of natural water samples with a pretreatment.

\begin{tabular}{lccc}
\hline $\begin{array}{l}\text { Sample } \\
\text { name }(4 \\
\text { locations })\end{array}$ & $\begin{array}{c}\text { Initial } \\
\text { concentration of } \\
\text { phosphate }(\mathrm{mg} / \mathrm{L})\end{array}$ & $\begin{array}{c}\text { Final } \\
\text { concentration of } \\
\text { phosphate }(\mathrm{mg} / \mathrm{L})\end{array}$ & $\begin{array}{c}\text { Removal } \\
(\%)\end{array}$ \\
\hline Location 1 & 2.916 & 0.000 & $100 \%$ \\
Location 2 & 0.784 & 0.000 & $100 \%$ \\
Location 3 & 1.411 & 0.000 & $100 \%$ \\
Location 4 & 2.369 & 0.000 & $100 \%$ \\
\hline
\end{tabular}

maintained, if needed, under control by applying the required particle dosage. It will reduce the labor cost and other costs for frequent water exchange and can control the amount of natural food or plankton availability in the pond at the required level.

\section{Conclusion}

In this study, phosphate removal behavior was studied using chemically synthesized vaterite polymorph of porous calcium carbonate (VPPCC) nanoparticles. VPPCC nanoparticles were synthesized using a wet-chemical method and characterized using XRD, FT-IR, SEM, and EDAX and by particle size analysis. The maximum phosphate removal of $100 \%$ removal was observed under $30 \mathrm{~min}$ of contact time with $0.15 \mathrm{~g}$ of particle dosage from an aqueous solution containing $2 \mathrm{mg} / \mathrm{L}$ of initial phosphate concentration. Results show that the adsorption process is less sensitive to the $\mathrm{pH}$ variation. The data fit well with the pseudo-second-order kinetic model and the Langmuir isotherm model which describe the adsorption mechanism is homogeneous monolayer chemisorption. There is no significant effect from the coexisting anions. According to the study, it can be concluded that the synthesized VPPCC nanoparticles are a potential candidate for removing phosphate ions in wastewater through developing a filtering system in the future to prevent eutrophication and associated health and environmental issues.

\section{Data Availability}

All the data have been submitted as a supplementary document with the manuscript.

\section{Conflicts of Interest}

There are no conflicts to declare.

\section{Acknowledgments}

This research was supported by the Department of Chemistry, Faculty of Science, University of Peradeniya and the Department of Aquaculture and Fisheries, Faculty of Livestock Fisheries and Nutrition, Wayamba University of Sri Lanka.

\section{Supplementary Materials}

Table S01: phosphate removal percentages at different contact times. Table S02: phosphate removal percentages at different VPCCNP dosages. Table S03: phosphate removal percentages at different $\mathrm{pH}$ values. Table S04: phosphate removal percentages at different concentrations. Table S05: $\mathrm{pH}$ change during the treatment. Table S06: parameters of kinetic study. Table S07: phosphate removal with different concentrations and parameters for Langmuir and Freundlich isotherms. Table S08: contact time optimization. Table S09: dosage optimization. Table S10: $\mathrm{pH}$ optimization. Table S11: initial concentration optimization*. Table S12: $\mathrm{pH}$ change during the treatment. (Supplementary Materials)

\section{References}

[1] "Selected multilateral environmental instruments In force for the U.S.," https://www.epa.gov/international-cooperation/ selected-multilateral-environmental-instruments-force-us.

[2] S. B. Bricker, B. Longstaff, W. Dennison et al., "Effects of nutrient enrichment in the nation's estuaries: a decade of change," Harmful Algae, vol. 8, pp. 21-32, 2008.

[3] J. Huisman and F. D. Hulot, "Population dynamics of harmful cyanobacteria," Harmful Cyanobacteria, vol. 3, pp. 143-176, 2005.

[4] H. Wang and H. Wang, "Mitigation of lake eutrophication: loosen nitrogen control and focus on phosphorus abatement," Progress in Natural Science, vol. 19, no. 10, pp. 1445-1451, 2009.

[5] A. A. Ansari and S. S. Gill, "Eutrophication: causes, consequences and control: volume 2. Eutrophication causes," Consequences Control, vol. 2, pp. 1-262, 2014.

[6] D. L. Correll, "The role of phosphorus in the eutrophication of receiving waters: a review," Journal of Environmental Quality, vol. 27, no. 2, pp. 261-266, 1998.

[7] Z. Zhu, H. Zeng, Y. Zhu et al., "Kinetics and thermodynamic study of phosphate adsorption on the porous biomorphgenetic composite of $\alpha$ - $\mathrm{Fe}_{2} \mathrm{O}_{3} / \mathrm{Fe}_{3} \mathrm{O}_{4} / \mathrm{C}$ with eucalyptus wood microstructure," Separation and Purification Technology, vol. 117, pp. 124-130, 2013. 
[8] P. A. Terry, "Removal of nitrates and phosphates by ion exchange with hydrotalcite," Environmental Engineering Science, vol. 26, no. 3, pp. 691-696, 2008.

[9] M. B. Mazis, R. B. Settle, and D. C. Leslie, "Elimination of phosphate detergents and psychological reactance," Journal of Marketing Research, vol. 10, no. 4, p. 390, 1973.

[10] L. L. Blackall, G. R. Crocetti, A. M. Saunders, and P. L. Bond, "A review and update of the microbiology of enhanced biological phosphorus removal in wastewater treatment plants," Journal of Microbiology, vol. 81, no. 1/4, pp. 681-691, 2002.

[11] E. Oguz, "Removal of phosphate from aqueous solution with blast furnace slag," Journal of Hazardous Materials, vol. 114, no. 1-3, pp. 131-137, 2004.

[12] K. Y. Chong, C. H. Chia, S. Zakaria, and M. S. Sajab, "Vaterite calcium carbonate for the adsorption of Congo red from aqueous solutions," Journal of Environmental Chemical Engineering, vol. 2, no. 4, pp. 2156-2161, 2014.

[13] H. B. Kwon, C. W. Lee, B. S. Jun, J. D. Yun, S. Y. Weon, and B. Koopman, "Recycling waste oyster shells for eutrophication control," Resources, Conservation and Recycling, vol. 41, no. 1, pp. 75-82, 2004.

[14] Y. S. Chena, W. C. Changb, S. H. Chuangc, and S. M. Chiangd, "Comparison of kinetic models for predicting phosphate adsorption onto spent alum sludge in a continuous fixed-bed column," Desalination and Water Treatment, vol. 32, no. 1-3, pp. 138-144, 2011.

[15] S. Jellali, M. A. Wahab, R. B. Hassine, A. H. Hamzaoui, and L. Bousselmi, "Adsorption characteristics of phosphorus from aqueous solutions onto phosphate mine wastes," Chemical Engineering Journal, vol. 169, no. 1-3, pp. 157-165, 2011.

[16] A. Ugurlu and B. Salman, "Phosphorus removal by fly ash," Environment International, vol. 24, no. 8, pp. 911-918, 1998.

[17] L. Johansson, "Blast furnace slag as phosphorus sorbents - column studies," Science of The Total Environment, vol. 229, no. 1-2, pp. 89-97, 1999.

[18] A. Kaasik, C. Vohla, R. Mõtlep, Ü. Mander, and K. Kirsimäe, "Hydrated calcareous oil-shale ash as potential filter media for phosphorus removal in constructed wetlands," Water Research, vol. 42, no. 4-5, pp. 1315-1323, 2008.

[19] F. Saberzadeh Sarvestani, H. Esmaeili, and B. Ramavandi, "Modification of Sargassum angustifolium by molybdate during a facile cultivation for high-rate phosphate removal from wastewater: structural characterization and adsorptive behavior," 3 Biotech, vol. 6, no. 2, 2016.

[20] M. Shams, I. Nabipour, S. Dobaradaran, B. Ramavandi, M. Qasemi, and M. Afsharnia, "An environmental friendly and cheap adsorbent (municipal solid waste compost ash) with high efficiency in removal of phosphorus from aqueous solution," Fresenius Environmental Bulletin, vol. 22, no. 3, pp. 722-726, 2013.

[21] S. Dunuweera and R. Rajapakse, "Synthesis of unstable vaterite polymorph of hollow calcium carbonate nanoparticles and encapsulation of the anticancer drug cisplatin," Journal of Advances in Medical and Pharmaceutical Sciences, vol. 10, no. 4, pp. 1-10, 2016.

[22] K. Z. Elwakeel, A. M. Elgarahy, and S. H. Mohammad, "Use of beach bivalve shells located at Port Said coast (Egypt) as a green approach for methylene blue removal," Journal of Environmental Chemical Engineering, vol. 5, no. 1, pp. 578-587, 2017.

[23] A. M. Elgarahy, K. Z. Elwakeel, G. A. Elshoubaky, and S. H. Mohammad, "Untapped sepia shell-based composite for the sorption of cationic and anionic dyes," Water, Air, \& Soil Pollution, vol. 230, no. 9, 2019.

[24] H. Mohammadifard and M. C. Amiri, "Evaluating $\mathrm{Cu}$ (II) removal from aqueous solutions with response surface methodology by using novel synthesized $\mathrm{CaCO} 3$ nanoparticles prepared in a colloidal gas aphron system," Chemical Engineering Communications, vol. 204, no. 4, pp. 476-484, 2017.

[25] K. G. M. D. Abeykoon, S. P. Dunuweera, D. N. D. Liyanage, and R. M. G. Rajapakse, "Removal of fluoride from aqueous solution by porous vaterite calcium carbonate nanoparticles," Materials Research Express, vol. 7, no. 3, 2020.

[26] J. K. Han, H. Y. Song, F. Saito, and B. T. Lee, "Synthesis of high purity nano-sized hydroxyapatite powder by microwavehydrothermal method," Materials Chemistry and Physics, vol. 99, no. 2-3, pp. 235-239, 2006.

[27] Y. S. Han, G. Hadiko, M. Fuji, and M. Takahashi, "Factors affecting the phase and morphology of $\mathrm{CaCO}_{3}$ prepared by a bubbling method," Journal of the European Ceramic Society, vol. 26, no. 4-5, pp. 843-847, 2006.

[28] S. Choi, Scholars Commons @ Laurier phosphorus removal using titanium dioxide nanoparticles in wastewater treatment, 2016.

[29] A. Ali, H. Zafar, M. Zia et al., "Synthesis, characterization, applications, and challenges of iron oxide nanoparticles," Nanotechnology, Science and Applications, vol. 9, pp. 49-67, 2016.

[30] S. T. Wang, W. Q. Wang, Z. R. Zhang, and H. You, "The impact of zinc oxide nanoparticles on phosphorus removal and the microbial community in activated sludge in an SBR," RSC Advances, vol. 6, no. 99, pp. 96706-96713, 2016.

[31] K. Karageorgiou, M. Paschalis, and G. N. Anastassakis, "Removal of phosphate species from solution by adsorption onto calcite used as natural adsorbent," Journal of Hazardous Materials, vol. 139, no. 3, pp. 447-452, 2007.

[32] S. Tadier, S. Rokidi, C. Rey, C. Combes, and P. G. Koutsoukos, "Crystal growth of aragonite in the presence of phosphate," Journal of Crystal Growth, vol. 458, pp. 44-52, 2017.

[33] A. Sarkar and S. Mahapatra, "Synthesis of all crystalline phases of anhydrous calcium carbonate," Crystal Growth \& Design, vol. 10, no. 5, pp. 2129-2135, 2010.

[34] Y. Wang, Y. X. Moo, C. Chen, P. Gunawan, and R. Xu, "Fast precipitation of uniform $\mathrm{CaCO}_{3}$ nanospheres and their transformation to hollow hydroxyapatite nanospheres," Journal of Colloid and Interface Science, vol. 352, no. 2, pp. 393-400, 2010.

[35] L. Wang, I. Sondi, and E. Matijević, "Preparation of uniform needle-like aragonite particles by homogeneous precipitation," Journal of Colloid and Interface Science, vol. 218, no. 2, pp. 545-553, 1999.

[36] L. Berzina-Cimdina and N. Borodajenko, "Research of calcium phosphates using Fourier transform infrared spectroscopy," Material Science, Engineering and Technology, 2012.

[37] J. Chen and L. Xiang, "Controllable synthesis of calcium carbonate polymorphs at different temperatures," Powder Technology, vol. 189, no. 1, pp. 64-69, 2009.

[38] A. Destainville, E. Champion, D. Bernache-Assollant, and E. Laborde, "Synthesis, characterization and thermal behavior of apatitic tricalcium phosphate," Materials Chemistry and Physics, vol. 80, no. 1, pp. 269-277, 2003.

[39] S. Meejoo, W. Maneeprakorn, and P. Winotai, "Phase and thermal stability of nanocrystalline hydroxyapatite prepared 
via microwave heating," Thermochimica Acta, vol. 447, no. 1, pp. 115-120, 2006.

[40] J. D. Rodriguez-Blanco, S. Shaw, P. Bots, T. Roncal-Herrero, and L. G. Benning, "The role of $\mathrm{pH}$ and $\mathrm{Mg}$ on the stability and crystallization of amorphous calcium carbonate," Journal of Alloys and Compounds, vol. 536, pp. S477-S479, 2012.

[41] Y. S. Ho and G. McKay, "Pseudo-second order model for sorption processes," Process Biochemistry, vol. 34, no. 5, pp. 451-465, 1999.

[42] S. Azizian, "Kinetic models of sorption: a theoretical analysis," Journal of Colloid and Interface Science, vol. 276, no. 1, pp. 4752, 2004.

[43] B. Singha and S. K. Das, "Adsorptive removal of $\mathrm{Cu}(\mathrm{II})$ from aqueous solution and industrial effluent using natural/agricultural wastes," Colloids and Surfaces B: Biointerfaces, vol. 107, pp. 97-106, 2013.

[44] B. H. Hameed, A. T. M. Din, and A. L. Ahmad, "Adsorption of methylene blue onto bamboo-based activated carbon: kinetics and equilibrium studies," Journal of Hazardous Materials, vol. 141, no. 3, pp. 819-825, 2007.

[45] J. He, K. Zhang, S. Wu et al., "Performance of novel hydroxyapatite nanowires in treatment of fluoride contaminated water," Journal of Hazardous Materials, vol. 303, pp. 119130, 2016.

[46] A. Khandelwal, N. Narayanan, E. Varghese, and S. Gupta, "Linear and nonlinear isotherm models and error analysis for the sorption of kresoxim-methyl in agricultural soils of India," Bulletin of Environmental Contamination and Toxicology, vol. 104, no. 4, pp. 503-510, 2020.

[47] A. O. Dada, A. P. Olalekan, A. M. Olatunya, and O. DADA, "Langmuir, Freundlich, Temkin and Dubinin-Radushkevich isotherms studies of equilibrium sorption of $\mathrm{Zn}^{2+}$ unto phosphoric acid modified rice husk," IOSR Journal of Applied Chemistry, vol. 3, no. 1, pp. 38-45, 2012.

[48] G. McKay, H. S. Blair, and J. R. Gardner, "Adsorption of dyes on chitin. I. Equilibrium studies," Journal of Applied Polymer Science, vol. 27, no. 8, pp. 3043-3057, 1982.

[49] M. H. Sayadi, B. Mansouri, E. Shahri, C. R. Tyler, H. Shekari, and J. Kharkan, "Exposure effects of iron oxide nanoparticles and iron salts in blackfish (Capoeta fusca): acute toxicity, bioaccumulation, depuration, and tissue histopathology," Chemosphere, vol. 247, p. 125900, 2020.

[50] K. K. Al-Zboon, "Phosphate removal by activated carbon-silica nanoparticles composite, kaolin, and olive cake," Environment, Development and Sustainability, vol. 20, no. 6, pp. 2707-2724, 2018.

[51] W. Huang, S. Wang, Z. Zhu et al., "Phosphate removal from wastewater using red mud," Journal of Hazardous Materials, vol. 158, no. 1, pp. 35-42, 2008.

[52] V. T. Trinh, T. M. P. Nguyen, H. T. Van et al., "Phosphate adsorption by silver nanoparticles-loaded activated carbon derived from tea residue," Scientific Reports, vol. 10, no. 1, article 3634, 2020.

[53] D. Cao, X. Jin, L. Gan, T. Wang, and Z. Chen, "Removal of phosphate using iron oxide nanoparticles synthesized by eucalyptus leaf extract in the presence of CTAB surfactant," Chemosphere, vol. 159, pp. 23-31, 2016.

[54] M. de Almeida, F. Vargas-Zerwes, L. Ferreira-Bastos et al., "Cation and anion monitoring in a wastewater treatment pilot project," Revista Facultad de Ingenieria, vol. 1, no. 76, pp. 82$89,2015$. 